\title{
An Exploratory Analysis of Title II Crowdfunding Success
}

\begin{abstract}
The passage of the Jumpstart Our Business Startups Act (JOBS Act) ushered in a new wave of equity crowdfunding in the United States. Title II of the JOBS Act aims to make it easier for new ventures to raise funds from accredited investors. The number of Title II crowdfunded projects is growing rapidly. Based on data for U.S. online 506(c) offerings across 17 leading platforms, more than $\$ 1.27$ billion in capital was committed to Title II projects through 2015. Our analysis of Title II offerings from these platforms reveals that real estate ventures are the single largest category with more than $\$ 316$ million in committed capital, yet only $34 \%$ of the crowdfunded real estate offerings receive the full amount of capital sought. Text mining of the real estate project descriptions reveals the critical facilitation role played by the successful crowdfunding platforms in reducing the information asymmetry between the entrepreneurs and investors by performing due diligence on the potential Title II investment opportunities.
\end{abstract}

\section{Introduction}

Crowdfunding is commonly defined as "an open call, essentially through the Internet, for the provision of financial resources either in the form of donation or in exchange for some form of reward and/or voting rights in order to support initiatives for specific purposes" [5]. Crowdfunding is a natural outcome of the convergence between microfinancing and crowdsourcing, but the development of crowdfunding in the United States was stymied by the legislature that imposed strict rules on public fundraising for business ventures. The Securities Act of 1933 and the Securities Exchange Act of 1934 (Securities and Exchange Acts) forbade public solicitation by new ventures without a prior registration of the securities being offered and the provision of detailed audited financial statements [17].

The Jumpstart Our Business Startups (JOBS Act) was passed in 2012 in response to the financial crisis of 2007-2008, which made it even harder for new ventures to raise capital. The JOBS Act was designed to address this challenge by requiring the SEC to adopt rules amending existing exemptions from registration and creating new exemptions for certain types of new venture fundraising [33]. Title II of the JOBS Act "directs the SEC to remove the prohibition on general solicitation or general advertising for securities offerings relying on Rule 506 provided that sales are limited to accredited investors and an issuer takes reasonable steps to verify that all purchasers of the securities are accredited investors. By requiring the SEC to remove this general solicitation restriction, Congress sought to make it easier for a company to find investors and thereby raise capital" [34]. Accredited investors include individuals with income in excess of $\$ 200,000$ per year for the last two years or net worth (excluding the primary residence) over $\$ 1$ million [15].

The SEC's final rules under Title II of the JOBS Act became effective on September 23, 2013. Based on the data we examined from 17 leading platforms, more than $\$ 1.27$ billion was raised under Title II through 2015 [13]. This is a rapidly growing area of finance, yet there is very little published research on Title II crowdfunding [37]. This is the research gap that we begin to address with the present study.

The broader goal of our study is to understand how Title II crowdfunding fits into the larger crowdfunding landscape. We seek to understand the types of business ventures that have been successful in raising capital under Title II. To address these questions, we explore a dataset containing 6,234 Title II crowdfunded projects aggregated across 17 crowdfunding platforms between September 23, 2013 and December 31, 2015. Our analysis reveals that real estate projects are the single largest category among Title II ventures, both in terms of the number of offerings as well as amount of capital commitments. While real estate is the dominant category, only $\sim 34 \%$ of the crowdfunded real estate projects reached their target. We report the results of text mining performed on the project description data that provide insights into the factors that might affect real estate project crowdfunding success.

The remainder of the manuscript is structured as follows. First, we present a brief introduction to crowdfunding and explain the key regulatory changes introduced by the JOBS Act. Next, we discuss prior crowdfunding research related to our effort. We address the methodology of our study, and we present the emergent insights from the analysis. We conclude 
with the discussion of our contributions to theory and practice.

\section{Crowdfunding overview}

The core function of crowdfunding is to solve the common need for capital among new business ventures and existing small businesses. Crowdfunding as a term covers a very broad spectrum of practices that allow entrepreneurs to raise capital. Four distinct types of crowdfunding projects are generally recognized, based on what the investors or donors receive in return for the funds that they provide to the entrepreneurs: donation-based, reward-based, loanbased, and equity- or securities-based [25]. To illustrate the differences among the four types of crowdfunded projects, we will discuss some prototypical examples of the crowdfunding platforms corresponding to each type.

GoFundMe.com is an example of a donation-based crowdfunding platform. The GoFundMe platform facilitates charitable donations to causes, projects, or people in need, with GoFundMe serving as the intermediary in the transaction. The donors who provide the funding have a choice of which projects to fund. GoFundMe campaigns include fundraising support for: individuals struggling with disease, disaster relief, memorials, and various educational initiatives. Importantly, the funds provided are donations and are not paid back to the donors.

Kickstarter exemplifies reward-based crowdfunding. Entrepreneurs and artists alike can post their projects on Kickstarter and solicit funding. The rewards available to potential backers vary by project type. The backers of an independent film may be invited to a private screening. The backers of a new electronics device or idea may be rewarded by getting a discount and an early delivery of the planned new product. Some reward-based crowdfunding projects may also include royalty-based crowdfunding of artistic ventures. For example, BandBackers.com allows investments in music projects with a royalty on the proceeds as the reward to the backers.

Peer-to-peer (P2P) lending exemplifies loan-based crowdfunding. LendingClub, SoFi, Prosper, Karrot and many other platforms in the $\mathrm{P} 2 \mathrm{P}$ lending space connect potential investors with individual borrowers. The unsecured personal loan space is growing rapidly. LendingClub reports having issued over $\$ 8$ billion in unsecured personal loans in 2015 [21].

Equity-based crowdfunding is a relatively new form of crowdfunding in the United States. This is in part due to the legal restrictions imposed by the Securities and Exchange Acts that required companies seeking to raise capital from the general public to register the securities and file extensive financial disclosures prior to the fundraising effort [17]. The securities laws and rules also impose periodic reporting requirements on the publicly-traded companies, creating a significant compliance cost and burden for these companies and erecting a barrier to public funding of certain entrepreneurial ventures.

In the next section, we highlight the key themes in crowdfunding research and focus on prior studies that shed light on certain factors that may positively influence success in debt and equity crowdfunding.

\section{Crowdfunding-related research}

One common goal of crowdfunding-related research is to understand the various factors that influence crowdfunding success. Given the relatively recent emergence and rapid evolution of equity crowdfunding as a phenomenon, the body of research remains relatively limited [6]. Much of the research on success in equity crowdfunding has been done outside of the United States. Australia was a pioneer in equity crowdfunding. The Australian Small Scale Offering Board was established in 2005 as the first platform of its kind brokering fundraising by small businesses [32]. The United Kingdom legalized equity crowdfunding in 2011 which led to the emergence of several equity crowdfunding platforms [3].

A study of factors that affect successful crowdfunding in the Australian Small Scale Offerings Board showed that human capital (number of board members) and the size of the equity offering (negative coefficient) were significantly correlated with the amount of funding received. Social capital (nonexecutive board members), intellectual capital (granted patents), number of staff, government grants, and number of years in business did not have significant relationships with the amount or speed of the capital raise [3]. The negative relationship between the amount of requested funding and the likelihood of meeting the funding objective is consistent across equity- [3] and reward-based platforms [11]. The higher the amount sought by the entrepreneurs, the less likely they were to receive the full commitment of funds.

Focusing on the dynamics of fundraising, a study that followed 492 projects on a crowdfunding platform in Switzerland showed that the first days after a project is announced serve as a good indicator of the project's chances of success. Successful projects gather support quickly, and the early support translates into successful fundraising campaigns [4]. Evidence from Kickstarter is consistent with the observations from the Swiss platform. Rapid contributions over the first few days after a project is made available on 
Kickstarter are positively correlated with funding success [11].

Information asymmetry is one of the key challenges that exist between the entrepreneurs and the potential investors. Entrepreneurs know more about the likelihood of the project success than the potential investors [38]. Several studies draw on signaling theory to understand how entrepreneurs may be able to reduce the information asymmetry through signals to investors and thus increase the likelihood of a successful crowdfunding campaign. Signaling theory posits that for signals to be effective, they must be visible and costly to obtain [10]. Consistent with the predictions of signaling theory, an analysis of 541 equity crowdfunded projects on Crowdcube (UK) showed that prior awards, professional investor backing, previous crowdfunding experience, grants, patents and an advisory board are all positively correlated with crowdfunding success [30].

Several studies have examined "weaker" signals in peer-to-peer lending that may be present in the narratives that the borrowers use to solicit funding. A study that examined linguistic style association with the outcome of loan requests on Prosper.com, a peerto-peer lending platform, showed that positive attitude and readability are positively correlated with a loan being funded [19]. Another study of loan defaults on Prosper.com revealed that grammatical errors were positively correlated with subsequent loan defaults [20]. The same study also suggested that certain lexical deception cues, e.g. the use of third person pronouns, are correlated with the higher likelihood of the borrower defaulting on the loan. A study of two European P2P lending platforms suggests that investors are perceptive to the lexical signals. The study found that loan requests containing spelling errors are less likely to receive funding [14].

Focusing on the potential mechanisms for reducing the information asymmetry between the entrepreneurs and the potential investors, a study of crowdfunding among angel investors revealed that syndicate investing is an emergent practice in equity crowdfunding [2]. Syndicates are groups of investors that are typically led by an experienced venture capitalist. The lead investors in the syndicates perform due diligence on the potential investments and thus reduce the information asymmetry that exists between the entrepreneurs and the potential investors. Some investors prefer to piggyback onto the due diligence, screening, and selection functions already performed by these experienced lead investors. An exploratory study of syndicate-based investments showed that syndicated investments dominated in terms of the overall funding commitments [2].
Crowdfunding as a phenomenon was widely expected to democratize both access to funding and access to potential investment opportunities. There is an emergent stream of research that suggests that although the Internet may remove the barriers to sharing information, the due diligence that needs to be done on the potential investments still serves as a barrier to connecting geographically remote investors with potential investment opportunities. Syndicate investments may help to overcome these challenges because the due diligence is performed by the lead angel investor who is typically geographically proximal to the potential investment opportunities. This is another proposed reason for the success of syndicate-based investing [2].

Crowdfunding platforms serve a number of important functions that ultimately influence the success of crowdfunding projects. In addition to bringing together the entrepreneurs and the potential investors, the platforms also generally serve the process coordination function. Further, the crowdfunding platforms can take on the function of educating both potential entrepreneurs and potential investors to help the overall growth of the marketplace [40].

To summarize the key insights from the extant research, information asymmetry between the entrepreneurs and the potential investors poses a significant challenge to successful crowdfunding. Entrepreneurs can signal the quality of the potential investment opportunity by demonstrating prior success and validation through venture capitalist involvement and the composition of the advisory boards. The crowdfunding platforms serve multiple functions in facilitating successful crowdfunding. The success of syndicate investments on crowdfunding platforms demonstrates how investors can pool their resources to reduce the information asymmetry. The results of research across multiple crowdfunding platforms also show that the size of the required funding is typically negatively correlated with fundraising success.

\section{Data and methodology}

The objective of the current exploratory study is to gain insight into the factors that influence success for projects that solicit investor funding under Title II of the JOBS Act. The insight on the success factors in Title II offerings would help us understand how Title II fits into the larger crowdfunding landscape. The exploratory focus of the study is appropriate, given the emergent nature of the crowdfunding industry and the relative scarcity of this type of research on Title II offerings $[8,12]$. We hope that the results presented 
here can serve as a part of the foundation for future empirical work and theory building [16].

The dataset for this study was obtained from Crowdnetic Corporation (Crowdnetic). Crowdnetic aggregates project-level data across 17 leading U.S. crowdfunding platforms targeting the opportunities created by Title II of the JOBS Act. This project is part of on-going collaboration aimed at understanding the fundamental drivers of success in securities-based crowdfunding. The dataset contains information about 6,234 Title II offerings from these 17 intermediaries, from inception through December 31, 2015.

Our analysis proceeded through two stages. First, we conducted an exploratory analysis of these Title II offerings to examine the dynamics of capital commitments over time as well as to evaluate the industry and geographic distribution of the offerings. In the second stage, we conducted more in-depth analysis of crowdfunded real estate ventures in particular.

Figure 1 illustrates the growth in the overall funding commitments between September 23, 2013the effective date of the SEC's rules under Title IIand December 31, 2015. More than \$233 million in capital commitments was recorded in the last quarter of 2013. The total capital commitments increased from $\$ 473$ million in 2014 to more than $\$ 570$ million in 2015. Even more impressively, the average amount of capital commitments increased dramatically from $\$ 181,486$ per successful issuer in 2014 to $\$ 493.659$ per successful issuer in 2015. Figure 2 illustrates this trend.

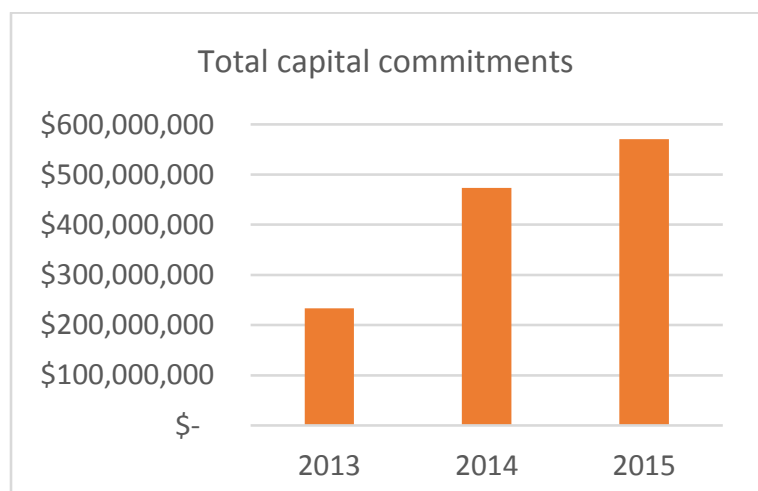

Figure 1. Total capital commitments in Title II projects

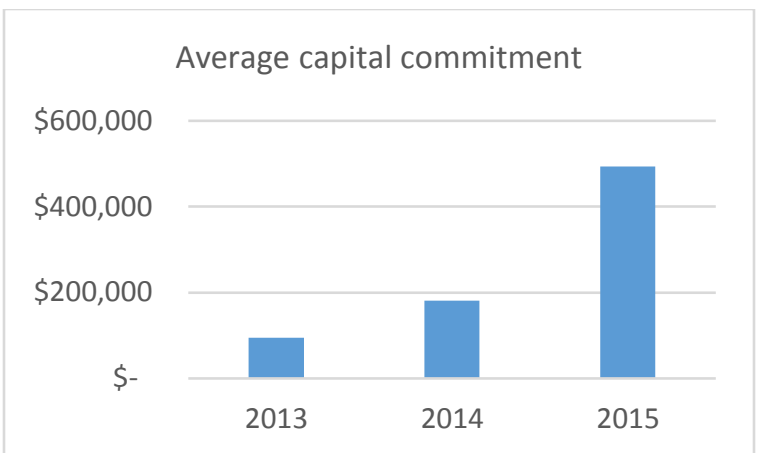

Figure 2. Total capital commitments in Title II projects

In the next step, we examined the geographic distribution of the offerings. Quite remarkably, there are Title II offerings from all 50 states, plus the District of Columbia and Puerto Rico. Focusing on the 48 contiguous states, we found that California had by far the largest number of offerings - 1,836 (29.5\%), followed by New York 692 (11\%) and Florida - 475 (7.6\%). Table 1 summarizes the number of offerings and the corresponding share of the total number of Title II offerings. Figure 3 illustrates the distribution of the projects among the 48 contiguous United States.

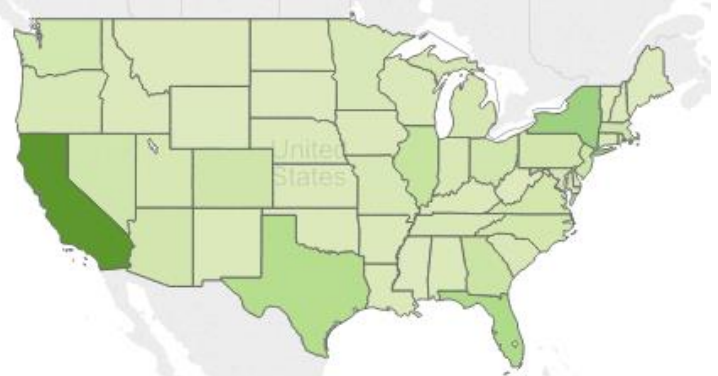

Figure 3. Geographic distribution of Title II projects

Table 1. Top 10 states by the number and share of Title II projects

\begin{tabular}{|l|r|r|}
\hline Business state & Number of offerings & \% of total number \\
\hline CA & 1,836 & $29.5 \%$ \\
\hline NY & 692 & $11.1 \%$ \\
\hline FL & 475 & $7.6 \%$ \\
\hline TX & 398 & $6.4 \%$ \\
\hline IL & 230 & $3.7 \%$ \\
\hline GA & 176 & $2.8 \%$ \\
\hline MA & 162 & $2.6 \%$ \\
\hline NJ & 161 & $2.6 \%$ \\
\hline CO & 149 & $2.4 \%$ \\
\hline NV & 125 & $2.0 \%$ \\
\hline
\end{tabular}


In the next step of our exploratory analysis, we examined the distribution of Title II offerings by industry. There are 292 industries from 8 sectors represented in the Title II offerings in our dataset, spanning the range from accounting services to aerospace. Table 2 summarizes the number of offerings and the contribution to the total for the top 10 industries.

Table 2. Top 10 industries by the number and share of Title II offerings

\begin{tabular}{|c|c|c|}
\hline Industry name & $\begin{array}{l}\text { Number of } \\
\text { projects }\end{array}$ & $\begin{array}{l}\% \text { of } \\
\text { total }\end{array}$ \\
\hline Real Estate & 453 & $7.3 \%$ \\
\hline Social Media & 312 & $5.0 \%$ \\
\hline App Software & 175 & $2.8 \%$ \\
\hline Digital Media/New Media & 119 & $1.9 \%$ \\
\hline Education K-12 & 111 & $1.8 \%$ \\
\hline Specialty Retail, Other & 104 & $1.7 \%$ \\
\hline Online \& Mobile Gaming & 98 & $1.6 \%$ \\
\hline Entertainment, Other & 93 & $1.5 \%$ \\
\hline Professional Services, Other & 86 & $1.4 \%$ \\
\hline $\begin{array}{l}\text { Business Software \& } \\
\text { Services }\end{array}$ & 83 & $1.3 \%$ \\
\hline Social Commerce & 83 & $1.3 \%$ \\
\hline
\end{tabular}

Next, we examined the industry distribution of successful offerings. The real estate industry holds by far the lion's share of successful offerings. Table 3 summarizes the distribution of successful offerings for the top 10 industries by the total number of successful offerings and provides average success rates..

Table 3. Top 10 industries by the number and share of Title II offerings

\begin{tabular}{|c|c|c|c|}
\hline Industry Name & $\begin{array}{l}\text { Number of } \\
\text { records }\end{array}$ & $\begin{array}{l}\text { Successful } \\
\text { offerings }\end{array}$ & $\begin{array}{l}\text { Avg. } \\
\text { success }\end{array}$ \\
\hline Real estate & 453 & 155 & $34.2 \%$ \\
\hline Biotechnology & 49 & 5 & $10.2 \%$ \\
\hline $\begin{array}{l}\text { Location-based } \\
\text { services }\end{array}$ & 57 & 4 & $7.0 \%$ \\
\hline Payment processing & 39 & 4 & $10.3 \%$ \\
\hline Social media & 312 & 3 & $1.0 \%$ \\
\hline Crowdfunding & 45 & 3 & $6.7 \%$ \\
\hline $\begin{array}{l}\text { Medical appliances } \\
\text { \& equipment }\end{array}$ & 43 & 3 & $7.0 \%$ \\
\hline $\begin{array}{l}\text { Business software \& } \\
\text { services }\end{array}$ & 83 & 2 & $2.4 \%$ \\
\hline Investments, other & 56 & 2 & $3.6 \%$ \\
\hline $\begin{array}{l}\text { Alternative energy, } \\
\text { other }\end{array}$ & 38 & 2 & $5.3 \%$ \\
\hline
\end{tabular}

Given the insights emergent from our exploratory analysis on the association between the project industry type and the number of successful projects, we decided to examine Title II real estate offerings in more detail. Geographically, the real estate projects are concentrated in California, New Jersey, Florida and New York, which account for $51.9 \%$ of all Title II real estate projects in our dataset. Figure 4 summarizes the distribution of Title II real-estate-related offerings throughout the 48 contiguous states.

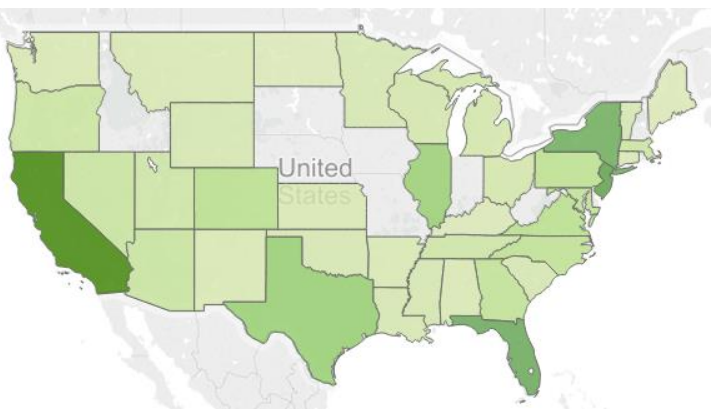

\section{Figure 4. Geographic distribution of Title II real-estate-related projects}

Focusing on the successful Title II real estate offerings, we find that the successful offerings are much more geographically concentrated. California, New York, New Jersey and Colorado capture 61.5\% of all successful real estate projects. Figure 5 summarizes the geographic distribution of successful Title II real-estate-related projects.

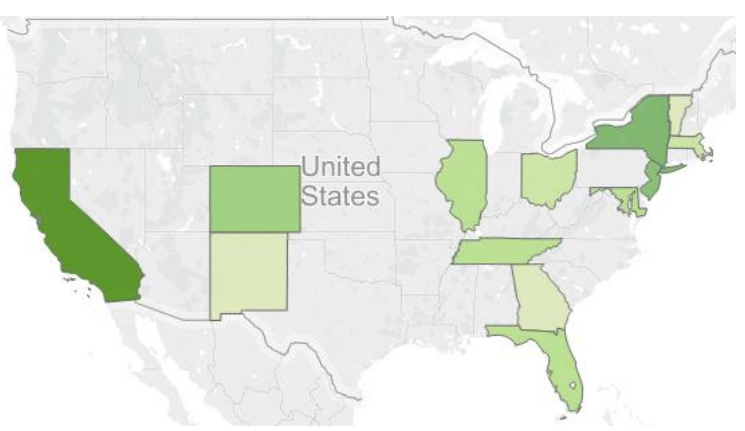

Figure 5. Geographic distribution of successful Title II real-estate-related projects

To gain further insight into the factors that may affect the success of Title II crowdfunding for real estate projects, we examined the effects of the issue type (equity, convertible debt, debt or real estate) as well as the minimum issue amount, i.e. the minimum target sought by a specific project. To assess the effects of the issue type and the minimum issue amount on the 
success of the projects, we created a dichotomous Success variable which we assigned the value of 1 if the amount of capital committed by the investors was greater or equal to the issue minimum amount and 0 otherwise. We transformed the minimum issue amount using the min-max transformation [27] to standardize the values. We used the SPSS version 23 software to assess the effects of the minimum issue amount on the probability of success using logistic regression. The result was significant $(\mathrm{B}=-20.596$, Wald statistic $=$ $15.877, \mathrm{df}=1, \mathrm{p}<0.001)$, indicating that the minimum issue amount was negatively related to the success of the offering.

We also examined the effects of the issue type on the success of real estate projects under Title II. The chi-square test was significant, indicating non-random association between the type of the issue and the success of the offering (Pearson chi-square $=201.7$, df $=3, \mathrm{p}<0.001)$. A clear pattern emerged after we visualized the success rate by the issue type. The success of offerings that involve real estate is much higher $(32 \%)$ than any of the other types of issues: equity (2\%), debt (2\%), and convertible debt (3\%). Figure 6 summarizes these results.

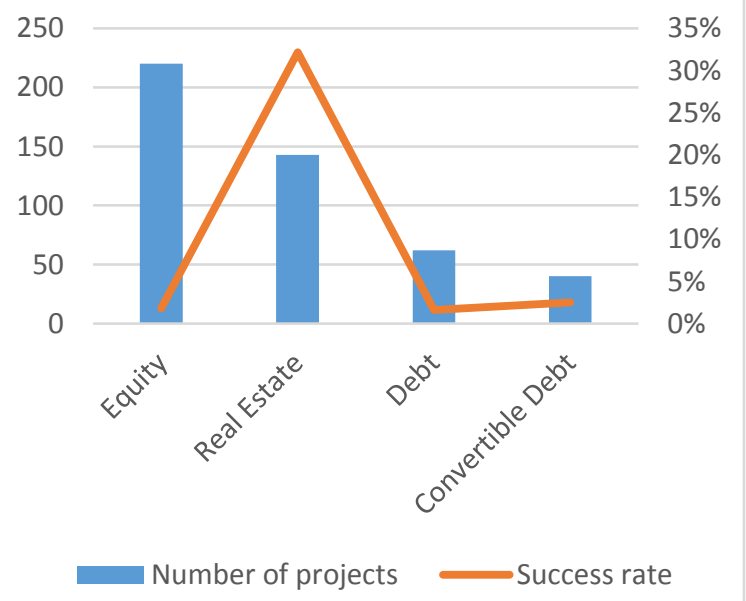

Figure 6. The number and success rate of Title II real estate offerings

In the next step of our exploratory analysis, we sought to identify lexical cues that might correlate with the successful real estate offerings.. Identification of these cues may yield insight into the factors that affect the investor decisions to participate in a specific real estate project.

Using the dataset of 453 real-estate-related offerings, of which 155 (34\%) received commitments equal to or greater than their target amounts, we built a naïve Bayes classification model using the bag of words transformation of the project descriptions to generate the feature set for the model. The naïve Bayes is a probabilistic classifier that is commonly used in text classification [23]. The method relies on joint probabilities of words and categories to estimate the probabilities of categories given a document. The "naïve" part refers to the assumption of word independence. This assumption makes the Naïve Bayes classifier computationally very efficient [26]. The bag of words representation of project descriptions transforms each project description into a feature set where each word or n-gram (combination of words) that is present in the collection of project descriptions becomes a feature. Despite its apparent simplicity, the bag of words transformation commonly outperforms linguistic and knowledge-based feature generation techniques [22,24].

We relied on Python version 3.5 and the Natural Language Toolkit (NLTK) version 3.0 to perform the text transformations and to build the naive Bayes classification model $[18,42]$. We removed stop words from the project descriptions prior to building the models. The stop words are frequently occurring words, e.g. 'a', 'as', 'of', etc., that effectively add noise to the data. Removal of the stop words typically improves the signal to noise ratio in text mining [39]. We built a series of predictive models using unigrams ( single words), bigrams, trigrams or a combination of the three.

The offering success (defined as receiving investment commitments equal to or in excess of the target amount) is the target variable in our models. Predicting project success or failure is a binary classification model. A good binary classification model will have comparatively few errors. Two types of errors can occur. First, a model may predict that a project will be successful, but it will actually fail to receive capital commitments. This is an example of a false positive (FP) error. The second type of model error would occur if a model predicts that an offering would fail to,receive full capital commitments but the offering would actually do so. This is an example of a false negative (FN) error. A classification matrix and associated metrics are typically used to assess the accuracy of classification models. Figure 7 illustrates a classification matrix.

\begin{tabular}{l|l|l|l|}
\multicolumn{3}{c}{} & \multicolumn{3}{c|}{ Predicted outcome } \\
\cline { 2 - 4 } & & Success & Failure \\
\cline { 2 - 4 } Actual & Success & True positive (TP) & False negative (FN) \\
\cline { 2 - 4 } outcome & Failure & False positive (FP) & True negative (TN) \\
\cline { 2 - 4 } & & C Classifle
\end{tabular}

Figure 7. Classification matrix for a binary classification model

A number of metrics are available to evaluate the performance of classification models. We are 
interested in maximizing the overall model accuracy, but also evaluating the accuracy of the models in relation to predicting the success of a specific offering. We will rely on the following metrics to assess our model performance.

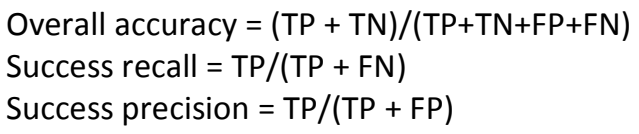

Success recall tells us what percentage of successful offerings our model identified correctly. Success precision tells us what percentage of the offerings that the model predicts will be successful actually were successful. To ascertain the model performance, we randomly partitioned our dataset into $70 \%$ training data and $30 \%$ test data and evaluated the model performance on the test data. Table 4 below summarizes the model performance.

Table 4. Model performance summary

\begin{tabular}{|l|r|r|r|}
\hline $\begin{array}{l}\text { Model } \\
\text { feature set }\end{array}$ & Accuracy & $\begin{array}{l}\text { Success } \\
\text { Precision }\end{array}$ & $\begin{array}{l}\text { Success } \\
\text { Recall }\end{array}$ \\
\hline unigrams & $89.4 \%$ & $78.7 \%$ & $88.1 \%$ \\
\hline bigrams & $87.2 \%$ & $75.5 \%$ & $88.9 \%$ \\
\hline trigrams & $79.4 \%$ & $63.4 \%$ & $93.8 \%$ \\
\hline $\begin{array}{l}\text { uni, bi and } \\
\text { trigrams }\end{array}$ & $89.4 \%$ & $84.6 \%$ & $86.3 \%$ \\
\hline
\end{tabular}

Rather remarkably, our models have relatively high overall accuracy. The model built using the combination of unigrams, bigrams and trigrams feature set has the best overall combination of performance metrics, with $89.4 \%$ overall accuracy and $84.6 \%$ precision in predicting success. This level of model accuracy suggests that there are strong lexical indicators of success within some of the project descriptions.

In the next step of the analysis, we extracted the lexical features with the highest association with offering success. The odds ratio reflects the increase in the odds of project success versus the base rate, and it is a commonly used technique for feature importance measurement [9]. Table 5 shows the top 5 features that are associated with offering success.

Table 5. Most important features

\begin{tabular}{|l|l|}
\hline Feature & Odds of success \\
\hline "commissioned by Patch" & $97.1: 1.0$ \\
\hline "developer is requesting" & $93.1: 1.0$ \\
\hline "appraisal commissioned by" & $82.4: 1.0$ \\
\hline
\end{tabular}

\begin{tabular}{|l|l|} 
"Patch of Land" & $79.7: 1.0$ \\
\hline "our due diligence" & $65.5: 1.0$ \\
\hline
\end{tabular}

\section{Discussion}

The primary objective of our study was to understand what type of entrepreneurial Title II offerings can be successful. The exploratory analysis of 6,234 offerings that were posted across 17 crowdfunding platforms in the period between September 2013 and December 2015 quickly revealed that, although there is a great diversity of companies that are trying to fundraise under this title of the JOBS Act, real estate ventures are by far the most successful category, both in terms of the number of offerings posted and the number of offerings that are successful in terms of receiving capital commitments.

Seeking to gain insight into the factors that may be responsible for the success of these real estate ventures, we performed text mining of the project descriptions. We were able to build fairly accurate models forecasting real estate project success and we identified a series of lexical indicators that are correlated with the success of these real estate ventures. These indicators pointed to the aggregate success of offerings conducted on one of the real estate platforms included in the dataset (Patch of Land). The remaining question that needs to be addressed is why these n-grams are so highly predictive of project success? One answer is that the above trigrams appear in the standard solicitation for real estate investments posted on the Patch of Land (POL) platform, which has seen a large volume of successful real estate offerings. A second possible explanation is that the use of standardized descriptive language or even standardized templates in offering materials may facilitate the search and review process for potential investors, providing them with seamless and efficient access to the relevant information they need to help them make informed investment decisions.

The particular intermediary that surfaced from the text mining analysis directly addresses the information asymmetry problem that can exist in certain crowdfunding settings by providing increased transparency and disclosure of relevant due diligence information, including: property and neighborhood descriptions; appraisals; downloadable documents; market data; risk ratings; and borrower history [34]. 
View the Property

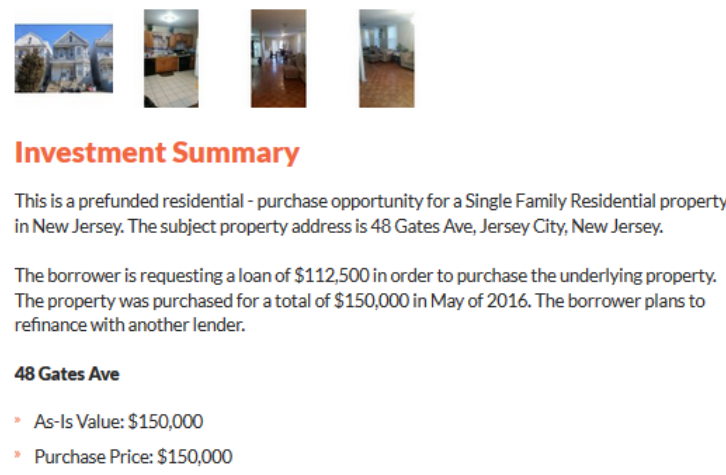

An independent third party appraisal commissioned by Patch of Land, shows an As-Is Value of $\$ 150,000$ for 48 Gates Ave. The LTV ratio is $75 \%$ and is in line with the data we found during our due diligence process. Our research shows the residential market surrounding the underlying property in this area of Jersey City is stable and supply outweighs demand.

Financial Overview

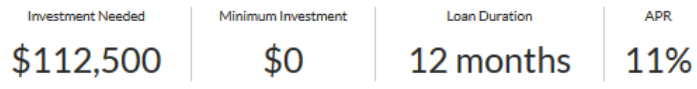

Figure 7. An example of a real estate investment opportunity posted on POL

The Patch of Land platform has streamlined the process of due diligence for potential real estate investment opportunities and provides immediate funding to the projects that have passed through its due diligence screening process. Following the investment in a project, POL then makes the projects available for participation by other investors who invest alongside POL. This overall process helps to reduce the uncertainty and information asymmetry that may be inherent in other types of investments. As of the end of 2015, POL reported having funded nearly $\$ 64$ million worth of real estate projects [41].

In both a syndicate-based business model as well as the model used by platforms that vet offerings before they are listed, the venture uncertainty inherent in early stage companies and the information asymmetry between entrepreneurs and potential investors can be materially reduced. These two approaches are distinct from each other in terms of the internalization of the process within the platform itself. Whereas a syndicate-based model relies upon a "community" solution in which individual venture capitalists or other lead investors assume the primary responsibility for screening potential investments, a platform-vetted model internalizes this task within the intermediary itself, using its own staff to pre-screen potential investments. The internalization of the process within an intermediary likely signals that the evaluation of new ventures, whether in real estate or other industries, can be standardized to a certain degree [25]. The evaluation of new technology or other ventures found in any syndicate-based model would require a unique approach to evaluating each venture separately [36]. This uniqueness challenge may be solved by relying upon the lead investors' expertise and willingness to perform the initial due diligence for the benefit of the syndicate.

\section{Contributions}

Out study makes a number of contributions to theory and practice. Our exploratory analysis of a unique dataset covering 17 leading securities-based crowdfunding platforms in the United States provides the empirical foundation for the emergent stream of research on equity crowdfunding that has been done in Europe and Australia [7,11]. In agreement with the observations made about certain platforms outside the United States, we find that a broad spectrum of new ventures across all sectors are attempting to raise capital in the United States under Title II of the JOBS Act.

We also find, based upon the dataset we examined, that real estate ventures in the aggregate represent the largest category of offerings receiving capital commitments under Title II of the JOBS Act in the two years since inception of Title II. These results are consistent with the theoretical propositions that crowds can be a useful source of different types of capital $[28,29]$. But we also find that while IT-enabled crowdsourcing platforms are expected to reduce search costs and lead to broader geographic sourcing decisions [1], the successful crowdfunded real estate ventures in our sample, are geographically concentrated suggesting that IT does not entirely eliminate geographic barriers to capital sourcing.

We also find that the information asymmetry that exists in real estate and other markets can be reduced or alleviated by establishing investment evaluation and due diligence processes to screen potential investment opportunities before they are offered to the community of investors on a platform. These results echo the findings for syndicate-based models led by experienced venture capitalists or other lead investors with unique expertise. [2].

Notably, there are also clear differences between a syndicate-based model and a platform-vetted model Whereas the syndicate model relies on a community of venture capitalists or others to perform the necessary task of due diligence, screening, and selection, those functions and processes, are internalized in a platformvetted model.

Prior research on the evaluation of risks in real estate investments suggests that there is a set of standard factors that need to be evaluated in real estate ventures, including: size, risk, liquidity, capital constraints, time horizon and developer expertise [25]. 
The relative invariance of these factors across real estate investment opportunities may be one factor in a platform's decision to internalize the assessment of these factors.

The above observations have implications in practice as well. The results of our exploratory analysis indicate that the success of a crowdfunding platform is related in part to the ability of the platform to solve the information asymmetry challenge and reduce friction in the investment process. Equity and debt crowdfunding platforms may be successful across other industries if they can develop standardized criteria for assessing specific types of investment opportunities. This will be particularly important, as Title III crowdfunding under the JOBS Act has recently come into effect $[31,35]$. The development of investment opportunity screening in the form of either a community-based solution or a platform-based service will likely play a key role in helping to promote success under Title II and Title III as the industry continues to evolve and gain traction.

Lastly, we would like to note that even though no research is without limitations, we have examined a representative dataset of over 6200 Title II offerings from all 50 states, drawn from 17 of the leading U.S. securities-based platforms, and covering all 8 sectors and 292 industries from the underlying taxonomy. We hope that the findings from our exploratory research will serve as a springboard for additional research in the area of securities-based and other forms of crowdfunding as this nascent industry continues to grow and develop.

\section{References}

[1] Afuah, A. and Tucci, C.L. Crowdsourcing as a solution to distant search. Academy of Management Review 37, 3 (2012), 355-375.

[2] Agrawal, A., Catalini, C., and Goldfarb, A. Are Syndicates the Killer App of Equity Crowdfunding? California Management Review 58, 2 (2014), 111125.

[3] Ahlers, G.K.C., Cumming, D., Günther, C., and Schweizer, D. Signaling in Equity Crowdfunding. Entrepreneurship Theory and Practice 39, 4 (2015), 955-980.

[4] Beier, M. and Wagner, K. User Behavior in Crowdfunding Platforms--Exploratory Evidence from Switzerland. 2016 49th Hawaii International Conference on System Sciences (HICSS), IEEE (2016), 3584-3593.

[5] Belleflamme, P., Lambert, T., and

Schwienbacher, A. Crowdfunding : An Industrial Organization. Business, (2010), 25-26.

[6] Brown, D.C. and Davies, S.W. Equity
Crowdfunding: Harnessing the Wisdom of the Crowd. Available at SSRN, (2015).

[7] Brüntje Dennis, G.O. Crowdfunding in Europe. FGF Studies in Small Business and Entrepreneurship 58, 2 (2016), 1-251.

[8] Busenitz, L.W., West, G.P., Sheperd, D., Nelson, T., Chandler, G.N., and Zacharakis, A.

Entrepreneurship research in emergence: Past trends and future directions. Journal of Management 29, 3 (2003), 285-308.

[9] Chen, J., Huang, H., Tian, S., and Qu, Y. Feature selection for text classification with Naive Bayes.

Expert Systems with Applications 36, 3 PART 1 (2009), 5432-5435.

[10] Connelly, B.L., Certo, S.T., Ireland, R.D., and Reutzel, C.R. Signaling theory: A review and assessment. Journal of Management 37, 1 (2011), 39-67.

[11] Cordova, A., Dolci, J., and Gianfrate, G. The Determinants of Crowdfunding Success: Evidence from Technology Projects. Procedia - Social and Behavioral Sciences 181, (2015), 115-124.

[12] Cornelius, B., Landstrom, H., and Persson, O. Entrepreneurial studies: The dynamic research front of a developing social science. Entrepreneurship: Theory and Practice 30, 3 (2006), 375-398.

[13] Crowdnetic. Crowdnetic's Quarterly Private Companies Publicly Raising Data Analysis. 2015. [14] Dorfleitner, G., Priberny, C., Schuster, S., et al. Description-text related soft information in peer-topeer lending - Evidence from two leading European platforms. Journal of Banking Finance 64, (2015), 169-187.

[15] E-CFR. Commodity and Securities Exchanges. 2016.

[16] Eisenhardt, K. Agency theory: An assessment and review. Academy of Management Review 14, 1 (1989), 57-74.

[17] Foley, A.J. and Paul, W. SEC Adopts Final Rules for Crowdfunding. Harvard Law School Forum on Corporate Governance and Financial Regulation, 2015.

[18] Foundation, P.S. Python 3.5 Documentation. Python Project Web Site, 2016.

https://docs.python.org/3/.

[19] Gao, Q. and Lin, M. Linguistic features and peer-to-peer loan quality: A machine learning approach. Available at SSRN, (2013).

[20] Gao, Q. and Lin, M. Lemon or Cherry? The Value of Texts in Debt Crowdfunding. Working Paper, (2015).

[21] LendingClub. Lending Club Statistics. 2016. [22] Lewis, D.D. and Jones, K.S. Natural language processing for information retrieval. Communications of the ACM 39, 1 (1996), 92-101. 
[23] Lewis, D.D., Nedellec, C., and Rouveirol, C. Naive (Bayes) at Forty: The Independence Assumption in Information Retrieval. Machine Learning: ECML-98, 1998, 4-15.

[24] Lewis, D.D. Text representation for intelligent text retrieval: A classification-oriented view. Textbased intelligent systems: current research and practice in information extraction and retrieval, (1992), 179-197.

[25] Marchand, F.I. Crowdfunding Real Estate: Institutions and Markets. An Institutional Comparison on the Growth-patterns and Behaviour of Crowdfunding Real Estate Markets in the Netherlands and United States. 2016.

[26] Michalski, R.S., Carbonell, J.G., and Mitchell, T.M. Machine learning: An artificial intelligence approach. Springer Science \& Business Media, 2013. [27] Peleg, S. and Rosenfeld, A. A min-max medial axis transformation. Pattern Analysis and Machine Intelligence, IEEE Transactions on, 2 (1981), 208210.

[28] Prpic, J. and Shukla, P. Crowd Science: Measurements, Models, and Methods. 2016 49th

Hawaii International Conference on System Sciences (HICSS), IEEE (2016), 4365-4374.

[29] Prpić, J., Shukla, P.P., Kietzmann, J.H., and McCarthy, I.P. How to work a crowd: Developing crowd capital through crowdsourcing. Business Horizons 58, 1 (2015), 77-85.

[30] Ralcheva, A. and Roosenboom, P. On the Road to Success in Equity Crowdfunding. Available at SSRN 2727742, (2016).

[31] Samuel Guzik. JOBS Act Crowdfunding Begins on May 16, 2016: Don't Get Busted for Solicitation! Crowdfund Insider, 2016.

http://www.crowdfundinsider.com/2016/03/83470jobs-act-crowdfunding-begins-on-may-16-2016-dontget-busted-for-solicitation/.

[32] Sandlund, J. Exploring ASSOB: A \$130 Million Crowdfunding Model that Works. The Crowd Cafe, 2012. http://www.thecrowdcafe.com/exploringassob-a-crowdfunding-model-that-works/.

[33] SEC. A Small Entity Compliance Guide. 2013.

[34] SEC. Eliminating the Prohibition on General

Solicitation and General Advertising in Certain

Offerings. 2013.

[35] SEC. Crowdfunding. 2014.

[36] Short, J.C., Ketchen, D.J., Shook, C.L., and

Ireland, R.D. The concept of " opportunity" in entrepreneurship research: Past accomplishments and future challenges. Journal of Management, (2009).

[37] Vogel, J.H. and Moll, B.S. Crowdfunding for Real Estate. The Real Estate Finance Journal, (2014), 5-16.

[38] Yan, S. Which signaling factors facilitate the success probability of equity crowdfunding? (2015). [39] Yang, J., Jiang, Y.-G., Hauptmann, A.G., and Ngo, C.-W. Evaluating bag-of-visual-words representations in scene classification. Proceedings of the international workshop on Workshop on multimedia information retrieval, ACM (2007), 197206.

[40] Younkin, P. and Kashkooli, K. What Problems Does Crowdfunding Solve? California Management Review 58, 2 (2016), 20-43.

[41] Patch of Land Media Guide. 2015. [42] NLTK Project. NLTK Web site, 2016. http://www.nltk.org/. 